\title{
Pharmacological doses of niacin stimulate the expression of genes involved in carnitine uptake and biosynthesis and improve the carnitine status of obese Zucker rats
}

\author{
Aline Couturier, Robert Ringseis, Erika Most and Klaus Eder
}

\begin{abstract}
Background: Activation of peroxisome proliferator-activated receptor (PPAR)a and PPARS causes an elevation of tissue carnitine concentrations through induction of genes involved in carnitine uptake [novel organic cation transporter 2, (OCTN2)], and carnitine biosynthesis [ $\gamma$-butyrobetaine dioxygenase (BBD), 4- $N$-trimethyl-aminobutyraldehyde dehydrogenase (TMABA-DH)]. Recent studies showed that administration of the plasma lipid-lowering drug niacin causes activation of PPARa and/or PPAR in tissues of obese Zucker rats, which have a compromised carnitine status and an impaired fatty acid oxidation capacity. Thus, we hypothesized that niacin administration to obese Zucker rats is also able to improve the diminished carnitine status of obese Zucker rats through PPAR-mediated stimulation of genes involved in carnitine uptake and biosynthesis.
\end{abstract}

Methods: To test this hypothesis, we used plasma, muscle and liver samples from a recent experiment with obese Zucker rats, which were fed either a niacin-adequate diet (30 mg niacin/ $\mathrm{kg}$ diet) or a diet with a pharmacological niacin dose (780 mg niacin/ $\mathrm{kg}$ diet), and determined concentrations of carnitine in tissues and mRNA and protein levels of genes critical for carnitine homeostasis (OCTN2, BBD, TMABA-DH). Statistical data analysis of all data was done by one-way ANOVA, and Fisher's multiple range test.

Results: Rats of the obese niacin group had higher concentrations of total carnitine in plasma, skeletal muscle and liver, higher mRNA and protein levels of OCTN2, BBD, and TMABA-DH in the liver and higher mRNA and protein levels of OCTN2 in skeletal muscle than those of the obese control group $(P<0.05)$, whereas rats of the obese control group had lower concentrations of total carnitine in plasma and skeletal muscle than lean rats $(P<0.05)$.

Conclusion: The results show for the first time that niacin administration stimulates the expression of genes involved in carnitine uptake and biosynthesis and improves the diminished carnitine status of obese Zucker rats. We assume that the induction of genes involved in carnitine uptake and biosynthesis by niacin administration is mediated by PPAR-activation.

Keywords: Niacin, Carnitine synthesis, Peroxisome proliferator-activated receptor a, Zucker rats

\footnotetext{
* Correspondence: robert.ringseis@ernaehrung.uni-giessen.de

Institute of Animal Nutrition and Nutrition Physiology,

Justus-Liebig-University Giessen, Heinrich-Buff-Ring 26-32, 35390 Giessen,

Germany
} 


\section{Background}

Niacin (nicotinic acid), a water-soluble vitamin of the B-complex, is involved in many metabolic pathways as a precursor of the redox coenzymes nicotinate adenine dinucleotide (NAD) and NAD phosphate [1]. Besides, niacin has potent plasma lipid-lowering effects and has long been used for clinical therapy of dislipidemia, particularly hypertriglyceridemia, due to the fact that niacin leads to decreased levels of triglycerides (TAG), very low-density lipoproteins (VLDL) and LDL in plasma [1-5]. Even though it has been established that niacin inhibits lipolysis in adipocytes and thereby reduces the supply of non-esterified fatty acids (NEFA) for hepatic TAG synthesis, this effect can only insufficiently explain the lipid-lowering effect because blood NEFA levels often rebound during long-term niacin treatment while the lipid-lowering effect remains $[1,6]$.

With regard to other effects of niacin, which may contribute to its lipid-lowering efficacy, it is noteworthy that acute administration of niacin causes an increase of the mRNA levels of peroxisome proliferator-activated receptor (PPAR) $\alpha$, PPAR $\delta$ and the PPAR co-activator PGC- $1 \alpha$ in tissues of male healthy subjects [7]. PPAR $\alpha$ and PPAR $\delta$ are ligand-dependent transcription factors which act as important metabolic regulators, especially in fatty acid catabolism, and are therefore abundantly expressed in tissues with high rates of fatty acid oxidation such as liver and skeletal muscle [8]. Endogenous ligand-activation is mediated by NEFA and, physiologically occurs during fasting when NEFA are released from adipose tissue und taken up into liver, muscle and other tissues $[9,10]$. Transcriptional regulation of genes by PPARs is mediated by binding of activated PPAR/ retinoid $\mathrm{X}$ receptor heterodimers to specific DNA sequences, called peroxisome proliferator response elements, present in and around the promoter of target genes $[8,11,12]$. Typical PPAR $\alpha$ and PPAR $\delta$ target genes are involved in all aspects of fatty acid catabolism, such as fatty acid uptake, intracellular fatty acid transport, mitochondrial fatty acid import, and peroxisomal and mitochondrial fatty acid oxidation $[8,13]$. In addition to its function in fatty acid catabolism, it has been recently established that PPAR $\alpha$ and PPAR $\delta$ are transcriptional regulators of genes involved in carnitine uptake, like novel organic cation transporter 2 (OCTN2, encoded by SLC22A5) [12,14], and/or carnitine biosynthesis, such as $\gamma$-butyrobetaine dioxygenase (BBD, encoded by BBOX1) and 4- $N$-trimethyl-aminobutyraldehyde dehydrogenase (TMABA-DH, encoded by ALDH9) [15,16]. This explains why physiological or pharmacological PPAR $\alpha$ and PPAR $\delta$ activation causes an elevation of carnitine concentrations in tissues because both, carnitine uptake and biosynthesis is stimulated $[14,17,18]$. Transcriptional regulation of genes involved in carnitine homeostasis by
PPAR $\alpha$ and PPAR $\delta$ is in line with their fundamental role for fatty acid catabolism because oxidation of fatty acids requires their import into the mitochondrial matrix, which is dependent on carnitine.

Interestingly, we have recently observed that administration of a pharmacological dose of niacin to obese Zucker rats causes elevated mRNA levels of a large set of PPAR $\alpha$ and PPAR $\delta$ target genes involved in fatty acid catabolism in skeletal muscle, and markedly lowers plasma lipid levels [19]. This indicates that niacin administration causes activation of PPAR $\alpha$ and/or PPAR $\delta$ in tissues of obese Zucker rats and that the niacin-induced improvement of fatty acid oxidation capacity of skeletal muscle contributes to the lipid-lowering effect of niacin. Since PPAR $\alpha$ and PPAR $\delta$ activation stimulates carnitine uptake and biosynthesis, it is likely that niacin enhances tissue carnitine concentrations, which also contributes to the improvement of mitochondrial fatty acid utilization. In light of this, we hypothesized that niacin administration causes a stimulation of the expression of genes involved in carnitine uptake and biosynthesis and thereby increases tissue carnitine concentrations. Considering that genetic or dietinduced obesity in rodents was found to result in a compromised carnitine status due to a reduced capacity of the body to synthesize and take up carnitine [20-22], it may be expected that such an effect of niacin is particularly useful in obesity. To test our hypothesis, we therefore used plasma, muscle and liver samples from a recent experiment with obese Zucker rats, an established genetic model of human obesity, and determined concentrations of carnitine and mRNA and protein levels of genes critical for carnitine homeostasis in liver and skeletal muscle [19].

\section{Methods}

\section{Animals and diet}

The obese (fa/fa) Zucker rat (Crl:ZUC-Lepr ${ }^{f a}$; Charles River, France) was used as animal model, which is a widely used genetic model of obesity, metabolic syndrome and diabetes. For this study, we used plasma, muscle and liver samples from an animal experiment performed recently by our group [19], in which twelve, 8- to 10-wk old male obese Zucker rats were randomly divided into two groups of each 10 rats. In addition, 10 male heterozygote lean $(\mathrm{fa} /+)$ Zucker rats were used. The rats received two different semi-purified diets which were composed according to the recommendations of the American Institute of Nutrition (AIN)-93G [23]. The first diet containing $30 \mathrm{mg}$ supplemented niacin per $\mathrm{kg}$ diet, which was sufficient to cover the niacin requirement, was fed to the lean group and the obese control group, whereas the second diet containing $780 \mathrm{mg}$ supplemented niacin (Lonza, Basel, Switzerland) per $\mathrm{kg}$ diet was fed to the obese niacin group. The lean group served as a "healthy" reference group in order to demonstrate the effect of the obese phenotype on 
carnitine homeostasis. A lean niacin group was not included in this experiment, because niacin at pharmacological doses does not exert a lipid-lowering action in healthy subjects with normal blood lipid levels and was not expected to cause an alteration of carnitine homeostasis. The diets were fed ad libitum and water was available ad libitum for a period of 28 days. Further details regarding diet composition, animal keeping and sample collection are shown in our previous publication [19]. In Accordance with Article 4 par. 3 of the German Animal Welfare Law all animals were humanely killed for scientific purpose approved by the Animal Welfare Officer of the Justus-Liebig-University, JLU No. 450_AZ.

Determination of plasma concentrations of nicotinic acid, nicotinamide (NAM), and nicotinuric acid (NUA)

The concentrations of nicotinic acid, NAM and NUA in plasma were determined by LC-MS/MS according to the method from Liu et al. [24] with slight modifications which have been reported recently [25].

\section{Determination of concentrations of total carnitine and carnitine precursors in plasma, muscle and liver}

Tandem mass spectrometry was used for determining the concentrations of free carnitine, acetyl-carnitine, and carnitine precursors [6-N-trimethyllysine (TML), butyrobetaine (BB)] in plasma, M. gastrocnemius and liver according the method of Hirche et al. [26]. Total carnitine was calculated as the sum of free carnitine and acetylcarnitine. Deuterated carnitine-d3 (Cambridge Isotype Laboratories, Andover, MA, USA) was used as internal standard.

\section{RNA isolation and qPCR (quantitative realtime RT-PCR) analysis}

Total RNA was isolated from $20 \mathrm{mg}$ skeletal muscle and liver tissue using Trizol $^{\mathrm{Is}}$ reagent (Invitrogen, Karlsruhe, Germany) according to the manufacturer's protocol. RNA isolation, cDNA synthesis and qPCR were performed as recently described [27]. The three most stable out of six tested potential reference genes were CANX, TOP1, $Y W H A Z$ in liver and RPL13, TOP1, YWHAZ in M. gastrocnemius. Data on qPCR performance for each gene measured in liver are shown in Table 1.

\section{Western blotting}

Homogenates were prepared from frozen tissue aliquots using RIPA buffer (50 mM Tris, $150 \mathrm{mM} \mathrm{NaCl}, 10 \%$ glycerol, $0.1 \%$ SDS, 1\% Trition X-100, 1 mM EDTA, 0.5\% deoxycholate, $1 \%$ protease inhibitor mix; $\mathrm{pH}$ 7.5). Using the bicinchoninic acid protein assay kit (Interchim, Mantluçon, France) the protein concentrations in the homogenates were determined with BSA as standard. $30 \mu \mathrm{g}$ protein of each homogenate was separated on $12.5 \%$ SDS-PAGE and finally electrotransferred to a nitrocellulosemembrane (Pall, Pensacola, USA). To verify the loading of equal amounts of protein Ponceau S (Carl Roth, Karlsruhe, Germany) staining was used. After incubation of the membranes with blocking solution for 1 hour, the membranes were incubated with the primary antibodies against OCTN2 (polyclonal Anti-Solute carrier family 22 member 5 antibody; Abcam, Cambridge, UK), BBD (monoclonal anti-BBOX1 antibody; Abcam, Cambridge, UK), TMABA-DH (polyclonal anti-TMABA-DH antibody, Abnova, Taipei, Taiwan), and glyceraldehyde-3-phosphate dehydrogenase (GAPDH) (monoclonal anti-GAPDH antibody, Abcam, Cambridge, UK) as a reference protein. The membranes were washed, and then incubated with a horseradish peroxidaseconjugated secondary monoclonal anti-mouse-IgG antibody (Sigma-Aldrich, Steinheim, Germany) for BBD and GAPDH and polyclonal anti-rabbit-IgG antibody (SigmaAldrich, Steinheim, Germany) for OCTN2 and TMABADH. Afterwards, blots were developed using ECL Select (GE Healthcare, München, Germany). The signal intensities of the specific bands were detected with a BioImaging system (Syngene Cambridge, UK) and quantified using Syngene GeneTools software (nonlinear dynamics).

\section{Statistics}

Statistical analysis of all data was done by one-way ANOVA using the Minitab Statistical Software (Rel. 13.0, State College, PA, USA). Means of the three groups were compared by Fisher's multiple range test. Means were considered significantly different for $\mathrm{P}<0.05$. Data presented are shown as means \pm SEM.

\section{Results}

Body weights, feed intake and feed conversion ratio Initial and final body weights were higher in the obese niacin group (362 $\pm 10 \mathrm{~g} ; 506 \pm 14 \mathrm{~g} ; \mathrm{n}=10$ ) and the obese control group ( $356 \pm 6$ g; $501 \pm 8$ g; $\mathrm{n}=10$ ) than in the lean group (270 \pm 3 g; $366 \pm 5$ g; $\mathrm{n}=10)(\mathrm{P}<0.05)$. Daily body weight gains and daily feed intake were higher in the obese niacin group $(5.09 \pm 0.22 \mathrm{~g} ; 26.6 \pm 0.7 \mathrm{~g} / \mathrm{d} ; \mathrm{n}=10)$ and the obese control group $(5.12 \pm 0.14 \mathrm{~g} ; 25.4 \pm 0.6 \mathrm{~g} / \mathrm{d} ; \mathrm{n}=10)$ than in the lean group $(3.35 \pm 0.10 \mathrm{~g} ; 19.7 \pm 0.3 \mathrm{~g} / \mathrm{d} ; \mathrm{n}=10)$ $(\mathrm{P}<0.05)$. Feed conversion ratio was higher in the lean group ( $5.92 \pm 0.13 \mathrm{~g}$ feed/g body weight gain; $\mathrm{n}=10)$ than in the obese niacin group $(5.27 \pm 0.14 \mathrm{~g}$ feed $/ \mathrm{g}$ body weight gain; $\mathrm{n}=10)$ and the obese control group $(4.98 \pm 0.09 \mathrm{~g}$ feed/g body weight gain; $\mathrm{n}=10)(\mathrm{P}<0.05)$. The obese niacin group and the obese control group did not differ with regard to these parameters.

\section{Concentration of NA and its metabolites (NAM and NUA) in plasma}

Rats of the obese niacin group had higher plasma NAM concentrations than those of the obese control group 
Table 1 Characteristics and performance data of the primers used for reference gene-stability measure $M$ and qPCR

\begin{tabular}{|c|c|c|c|c|c|c|c|c|c|}
\hline \multirow{2}{*}{$\begin{array}{l}\text { Gene } \\
\text { symbol }\end{array}$} & \multirow{2}{*}{$\begin{array}{l}\text { Primer sequence (forward, } \\
\text { reverse; from } 5^{\prime} \text { to } 3^{\prime} \text { ) }\end{array}$} & \multirow{2}{*}{$\begin{array}{l}\text { NCBI } \\
\text { GeneBank }\end{array}$} & \multirow{2}{*}{$\begin{array}{l}\text { Product } \\
\text { size (bp) }\end{array}$} & \multicolumn{3}{|c|}{ Skeletal muscle } & \multicolumn{3}{|c|}{ Liver } \\
\hline & & & & Slope & $\mathrm{R}^{2 \#}$ & Efficiency* & Slope & $\mathrm{R}^{2 \#}$ & Efficiency* \\
\hline \multirow[t]{2}{*}{$\overline{A C A D L}$} & AAGGATTTATTAAGGGCAAGAAGC & NM_012819.1 & $380 \mathrm{bp}$ & -4.45 & 1.000 & 1.68 & -3.54 & 0.999 & 1.92 \\
\hline & GGAAGCGGAGGCGGAGTC & & & & & & & & \\
\hline \multirow[t]{2}{*}{ ACADM } & CAAGAGAGCCTGGGAACTTG & NM_016986.2 & 154 bp & -3.29 & 0.998 & 2.01 & -3.29 & 0.998 & 2.01 \\
\hline & CCCCAAAGAATTTGCTTCAA & & & & & & & & \\
\hline \multirow[t]{2}{*}{ ACADS } & ACATCTCTTCCCCACATCGC & NM_022512.2 & 204 bp & -2.98 & 0.999 & 2.16 & -3.55 & 0.999 & 1.91 \\
\hline & CCGAACTTCAGGATGGGTCC & & & & & & & & \\
\hline \multirow[t]{2}{*}{ ACOX1 } & CTGGGCTGAAGGCTITTACT & NM_017340.2 & 172 bp & -3.60 & 0.997 & 1.90 & -3.97 & 0.999 & 1.79 \\
\hline & GCTGTCTGCAGCATCATAAC & & & & & & & & \\
\hline \multirow[t]{2}{*}{ ALDH9 } & TTGAGCGGCTGCGACACGAC & NM_022273.2 & $82 \mathrm{bp}$ & & - & & -3.42 & 0.999 & 1.96 \\
\hline & TGACCTCGCTCCTCCGCGTA & & & & & & & & \\
\hline \multirow[t]{2}{*}{ ATP5B } & GCACCGTCAGAACTATTGCT & NM_134364 & 203 bp & -3.58 & 0.998 & 1.90 & -3.33 & 0.999 & 2.00 \\
\hline & GAATTCAGGAGCCTCAGCAT & & & & & & & & \\
\hline \multirow[t]{2}{*}{$\mathrm{BBOX} 1$} & GGATGGGGCTCGCTTGATGCA & NM_022629.1 & $281 \mathrm{bp}$ & & - & & -3.38 & 0.997 & 1.98 \\
\hline & GGAGTCCTGCTCTGGCCTCCT & & & & & & & & \\
\hline \multirow[t]{2}{*}{ CANX } & CCAGATGCAGATCTGAAGAC & NM_172008 & $175 \mathrm{bp}$ & -3.30 & 1.000 & 2.01 & -3.45 & 0.999 & 1.95 \\
\hline & CTGGGTCCTCAATTTCACGT & & & & & & & & \\
\hline \multirow[t]{2}{*}{$\mathrm{MDH} 1$} & CAGACAAAGAAGAGGTTGCC & NM_033235.1 & 206 bp & -3.41 & 0.999 & 1.96 & -3.27 & 0.999 & 2.02 \\
\hline & CGTCAGGCAGTTTGTATTGG & & & & & & & & \\
\hline \multirow[t]{2}{*}{ RPL13 } & CTTAAATTGGCCACGCAGCT & XR_086310 & 198 bp & -3.20 & 0.999 & 2.05 & -3.53 & 0.997 & 1.92 \\
\hline & CTTCTCAACGTCTTGCTCTG & & & & & & & & \\
\hline \multirow[t]{2}{*}{ SLC22A5 } & GAACTCACGAGCCTCGCACGC & NM_019269.1 & 117 bp & -2.98 & 1.000 & 2.16 & -3.51 & 1.000 & 1.93 \\
\hline & TCGTCGTAGTCCCGCATGCC & & & & & & & & \\
\hline \multirow[t]{2}{*}{ TOP1 } & GAAGAACGCTATCCAGAAGG & NM_022615 & 137 bp & -3.45 & 0.999 & 1.95 & -3.34 & 0.998 & 1.99 \\
\hline & GCTTTGGGACTCAGCTTCAT & & & & & & & & \\
\hline \multirow[t]{2}{*}{ YWHAZ } & GACGGAAGGTGCTGAGAAA & NM_013011 & 198 bp & -3.11 & 0.999 & 2.10 & -3.30 & 0.999 & 2.01 \\
\hline & GCAGCAACCTCAGCCAAGT & & & & & & & & \\
\hline
\end{tabular}

${ }^{\#}$ Coefficient of determination of the standard curve. ${ }^{*}$ The efficiency was determined by $\left[10^{- \text {slope }}\right]$.

and the lean group $(1.2 \pm 0.09 ; 0.6 \pm 0.07 ; 0.5 \pm 0.03 \mu \mathrm{g} / \mathrm{ml}$; $\mathrm{n}=10 ; \mathrm{P}<0.05)$. The plasma NAM concentration did not differ between the obese control group and the lean group. Plasma concentrations of NA and NUA were below the limit of detection $(0.01 \mu \mathrm{g} / \mathrm{ml})$ in all groups.

\section{Concentration of carnitine and its precursors in plasma, gastrocnemius muscle and liver}

The concentration of total carnitine in plasma and muscle was higher in the lean group than in the two obese groups, but it was higher in the obese niacin group than in the obese control group $(\mathrm{P}<0.05$; Table 2$)$. Concentration of total carnitine in the liver was also higher in the obese niacin group than in the obese control group $(\mathrm{P}<0.05$; Table 2), whereas it did not differ between the lean group and the obese control group.
Concentrations of the carnitine precursor BB in plasma, muscle and liver were higher in the lean group than in the obese control group and the obese niacin group $(\mathrm{P}<0.05$; Table 2), but did not differ between the two obese groups. The concentration of the carnitine precursor TML in plasma was higher in the lean group than in the two obese groups $(\mathrm{P}<0.05$; Table 2$)$, whereas it was not different between these groups in liver and skeletal muscle.

\section{Relative mRNA concentrations of PPAR target genes} involved in lipid metabolism of liver and gastrocnemius muscle

To investigate whether niacin causes an activation of PPAR $\alpha$ and/or PPAR $\delta$ in muscle and liver, we determined the mRNA concentrations of classical PPAR target genes involved in fatty acid oxidation in these tissues. Relative 
Table 2 Concentrations of total carnitine and its precursors (BB and TML) in plasma, liver and gastrocnemius muscle of lean rats (Lean), obese Zucker rats fed a control diet (Obese Control) or obese Zucker rats fed a diet supplemented with $780 \mathrm{mg} \mathrm{niacin} / \mathbf{k g}$ diet (Obese Niacin) for $4 \mathbf{w k}^{\mathbf{1}}$

\begin{tabular}{lccc}
\hline & Lean & Obese control & Obese niacin \\
\hline Plasma ( $\mu$ mol/l) & & & \\
Total Carnitine & $62.4 \pm 2.1^{\mathrm{a}}$ & $39.5 \pm 1.1^{\mathrm{c}}$ & $48.4 \pm 2.9^{\mathrm{b}}$ \\
Y-Butyrobetaine (BB) & $0.75 \pm 0.04^{\mathrm{a}}$ & $0.36 \pm 0.04^{\mathrm{b}}$ & $0.42 \pm 0.05^{\mathrm{b}}$ \\
Trimethyllysine (TML) & $0.89 \pm 0.03^{\mathrm{a}}$ & $0.64 \pm 0.02^{\mathrm{b}}$ & $0.67 \pm 0.03^{\mathrm{b}}$ \\
Skeletal muscle (nmol/g) & & & \\
Total Carnitine & $730 \pm 26^{\mathrm{a}}$ & $602 \pm 28^{\mathrm{b}}$ & $681 \pm 28^{\mathrm{a}}$ \\
Y-Butyrobetaine (BB) & $10.9 \pm 0.5^{\mathrm{a}}$ & $8.42 \pm 0.40^{\mathrm{ab}}$ & $7.31 \pm 0.65^{\mathrm{b}}$ \\
Trimethyllysine (TML) & $73.7 \pm 11.5$ & $58.7 \pm 10.5$ & $58.8 \pm 3.8$ \\
Liver (nmol/g) & & & \\
Total Carnitine & $289 \pm 10^{\mathrm{b}}$ & $298 \pm 7^{\mathrm{b}}$ & $334 \pm 12^{\mathrm{a}}$ \\
Y-Butyrobetaine (BB) & $3.32 \pm 0.35^{\mathrm{a}}$ & $2.12 \pm 0.13^{\mathrm{b}}$ & $1.93 \pm 0.17^{\mathrm{b}}$ \\
Trimethyllysine (TML) & $16.5 \pm 1.6$ & $13.5 \pm 0.7$ & $14.1 \pm 0.8$ \\
\hline
\end{tabular}

${ }^{1}$ Data are expressed as means \pm SEM. $n=10$ rats/group. ${ }^{a, b}$ Values with different superscript letters differ, $\mathrm{P}<0.05$.

mRNA concentrations of acyl-CoA-oxidase 1 (ACOX1), short-chain acyl-CoA-dehydrogenase (ACADS), mediumchain acyl-CoA-dehydrogenase (ACADM) and long-chain acyl-CoA-dehydrogenase (ACADL), which are involved in peroxisomal and/or mitochondrial $\beta$-oxidation, in liver and skeletal muscle were higher in the obese niacin group than in the obese control group and the lean group $(\mathrm{P}<0.05$; Table 3$)$.

Relative mRNA concentrations of genes involved in carnitine uptake in liver and gastrocnemius muscle and carnitine synthesis in the liver

To study whether niacin influences the expression of genes involved in carnitine uptake in liver and muscle and hepatic carnitine synthesis, we evaluated the mRNA concentrations of SLC22A5, BBOX1 and ALDH9 in liver and muscle, respectively. BBOX1 and ALDH9 were considered only in the liver, because the liver is the major organ responsible for carnitine biosynthesis. In the liver, the mRNA concentrations of SLC22A5, BBOX1 and ALDH9 were higher in the obese niacin group than in the obese control group and the lean group $(\mathrm{P}<0.05$; Table 3), but they were not different between the obese control group and the lean group. The mRNA concentration of SLC22A5 in gastrocnemius muscle was also higher in the obese niacin group than in the obese control group (Table 3), but did not differ between the obese niacin group and the lean group.

\section{Relative protein concentrations of genes involved in} carnitine uptake in liver and gastrocnemius muscle and carnitine synthesis in the liver

Relative protein concentrations of OCTN2, BBD, and TMABA-DH in the liver were lower in the obese control group than in the obese niacin group and the lean group

Table 3 Relative mRNA concentrations of PPARa and PPAR $\delta$ target genes involved in $\beta$-oxidation (ACOX1, SCAD, MCAD, LCAD) and genes involved in carnitine uptake (OCTN2) and biosynthesis (BBD, TMABA-DH) in liver and gastrocnemius muscle of lean rats (Lean), obese Zucker rats fed a control diet (Obese Control) or obese Zucker rats fed a diet supplemented with $780 \mathrm{mg}$ niacin/kg diet (Obese Niacin) for $4 \mathbf{w k}^{\mathbf{1}}$

\begin{tabular}{lccc}
\hline & Lean & $\begin{array}{c}\text { Obese control } \\
\text { Obese niacin } \\
\text { Skeletal muscle }\end{array}$ & Relative mRNA concentration (fold of obese control = 1.00) \\
ACOX1 & $1.49 \pm 0.29^{\mathrm{ab}}$ & $1.00 \pm 0.21^{\mathrm{b}}$ & $1.89 \pm 0.36^{\mathrm{a}}$ \\
SCAD & $1.68 \pm 0.46^{\mathrm{ab}}$ & $1.00 \pm 0.40^{\mathrm{b}}$ & $2.69 \pm 0.70^{\mathrm{a}}$ \\
MCAD & $1.40 \pm 0.30^{\mathrm{ab}}$ & $1.00 \pm 0.34^{\mathrm{b}}$ & $2.24 \pm 0.47^{\mathrm{a}}$ \\
LCAD & $1.43 \pm 0.46^{\mathrm{ab}}$ & $1.00 \pm 0.25^{\mathrm{b}}$ & $3.78 \pm 1.32^{\mathrm{a}}$ \\
SLC22A5 & $1.25 \pm 0.31^{\mathrm{ab}}$ & $1.00 \pm 0.18^{\mathrm{b}}$ & $1.93 \pm 0.42^{\mathrm{a}}$ \\
Liver & & & $1.42 \pm 0.07^{\mathrm{a}}$ \\
ACOX1 & $0.92 \pm 0.14^{\mathrm{b}}$ & $1.00 \pm 0.12^{\mathrm{b}}$ & $1.57 \pm 0.08^{\mathrm{a}}$ \\
SCAD & $0.91 \pm 0.09^{\mathrm{b}}$ & $1.00 \pm 0.14^{\mathrm{b}}$ & $1.76 \pm 0.22^{\mathrm{a}}$ \\
MCAD & $1.19 \pm 0.13^{\mathrm{b}}$ & $1.00 \pm 0.14^{\mathrm{b}}$ & $1.57 \pm 0.08^{\mathrm{a}}$ \\
LCAD & $0.99 \pm 0.17^{\mathrm{b}}$ & $1.00 \pm 0.14^{\mathrm{b}}$ & $1.42 \pm 0.12^{\mathrm{a}}$ \\
SLC22A5 & $0.78 \pm 0.06^{\mathrm{b}}$ & $1.00 \pm 0.07^{\mathrm{b}}$ & $1.54 \pm 0.06^{\mathrm{a}}$ \\
BBOX1 & $0.76 \pm 0.08^{\mathrm{b}}$ & $1.00 \pm 0.08^{\mathrm{b}}$ & $1.40 \pm 0.14^{\mathrm{a}}$ \\
ALDH9 & $1.00 \pm 0.08^{\mathrm{b}}$ & $1.00 \pm 0.08^{\mathrm{b}}$ & \\
\hline
\end{tabular}

${ }^{1}$ Data are expressed as means \pm SEM. $n=10$ rats/group. ${ }^{\text {a,b }}$ Values with different superscript letters differ, $\mathrm{P}<0.05$. 
$(\mathrm{P}<0.05$; Figure 1$)$, but they were not different between the obese niacin group and the lean group. Relative protein concentration of OCTN2 in muscle was higher in the obese niacin group than in the obese control group and the lean group $(\mathrm{P}<0.05$; Figure 2$)$.

\section{Discussion}

In the present study, we tested the hypothesis that niacin administration to obese Zucker rats is able to improve the carnitine status of obese Zucker rats through PPARstimulated expression of genes involved in carnitine uptake and biosynthesis. As expected, administration of $780 \mathrm{mg}$ niacin/ $\mathrm{kg}$ diet for $4 \mathrm{wk}$ to obese Zucker rats resulted in an about 2-fold elevation of plasma NAM levels compared to obese control rats, which received a physiological niacin dose $(30 \mathrm{mg} / \mathrm{kg}$ diet) sufficient to cover their niacin requirement. This elevation of plasma NAM levels was in the range of that reported in other studies, in which a similar niacin dose was fed to rats $[25,28]$. The finding that nicotinic acid and NUA were not detectable was also not unexpected, because nicotinic acid from the diet is rapidly converted to NAD and NAM in the intestine and liver, from which NAM is released into the blood stream [29]. Nicotinic acid and NUA can be found in the systemic blood at significant levels only when nicotinic acid is administered either i.v. or as a fast release preparation, because nicotinic acid is then activated by combination with coenzyme A (CoA) to form nicotinyl-CoA, which is then conjugated with glycine to NUA [30]. A key finding of the present study was that niacin administration in pharmacological doses results in enhanced carnitine concentrations in plasma, skeletal muscle and liver and improves the diminished carnitine status of obese Zucker rats indicating that niacin increases carnitine uptake into tissues and hepatic carnitine synthesis. Although it has been proposed that the carnitine precursors TML and $\mathrm{BB}$ are rate-limiting for carnitine biosynthesis [31], we found no difference in the concentrations of carnitine precursors between the two obese groups, despite elevated carnitine concentrations in plasma and liver in the obese niacin group. However, the observation from the present study that mRNA and protein levels of OCTN2, BBD and TMABA-DH were significantly increased in the liver and skeletal muscle of the obese niacin group compared to the obese control group rather suggests that the rate of carnitine biosynthesis and uptake were elevated through stimulating expression of genes involved in carnitine homeostasis. Noteworthy, BB is also a good substrate for OCTN2 $[32,33]$ and the liver has a high capacity to convert $\mathrm{BB}$ into carnitine [34]. Thus, it is likely that the niacininduced increase in the expression of OCTN2 in the liver also contributed to an elevated carnitine biosynthesis rate in the liver.

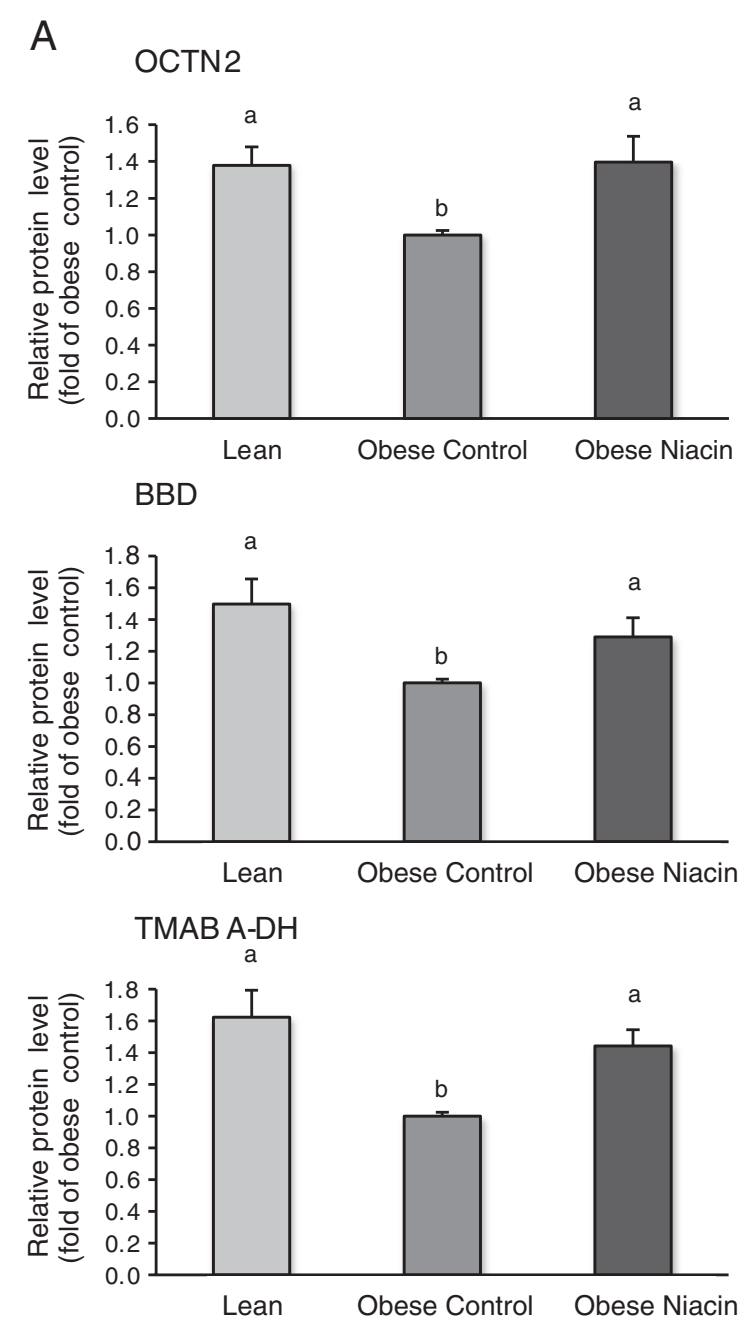

\section{B}

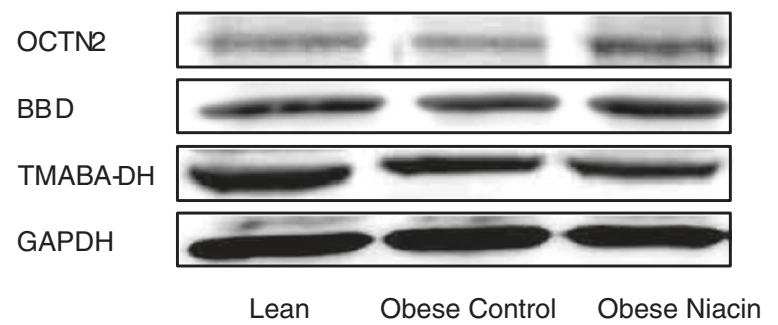

Figure 1 Relative protein levels of OCTN2, BBD and TMABA-DH in liver of lean rats (Lean), obese Zucker rats fed a control diet (Obese Control) or obese Zucker rats fed a diet supplemented with $780 \mathrm{mg} \mathrm{niacin} / \mathrm{kg}$ diet (Obese Niacin) for 4 wk. (A) Bars represent means \pm SEM, $n=10$ /group. Means without a common letter differ, $P<0.05$. (B) Representative immunoblots specific to OCTN2, BBD, TMABA-DH and GAPDH as internal control are shown for one animal per group; immunoblots for the other animals revealed similar results. 




\section{B}

OCTN2

GAPDH

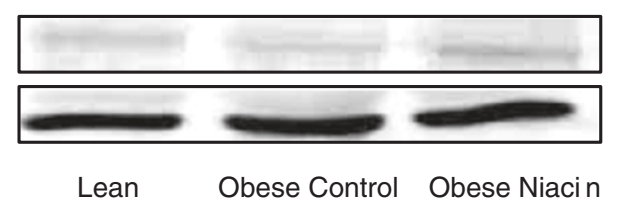

Figure 2 Relative protein level of OCTN2 in M. gastrocnemius of lean rats (Lean), obese Zucker rats fed a control diet (Obese Control) or obese Zucker rats fed a diet supplemented with $\mathbf{7 8 0} \mathbf{~ m g ~ n i a c i n} / \mathbf{k g}$ diet (Obese Niacin) for $\mathbf{4}$ wk. (A) Bars represent means \pm SEM, $n=10 /$ group. Means without a common letter differ, $\mathrm{P}<0.05$. (B) Representative immunoblots specific to OCTN2 and GAPDH as internal control are shown for one animal per group; immunoblots for the other animals revealed similar results.

In view of recent indications that niacin causes activation of PPAR $\alpha$ and/or PPAR $\delta$ in tissues of rats [19], and activation of both of them is known to stimulate carnitine uptake and biosynthesis [12,14-18], we studied whether niacin resulted in the activation of PPAR $\alpha$ and PPAR $\delta$ in the liver and skeletal muscle of obese Zucker rats. We observed that several PPAR $\alpha$ and PPAR $\delta$ target genes, such as ACOX1, ACADS, ACADM, ACADL, encoding enzymes of fatty acid $\beta$-oxidation were elevated in both, liver and skeletal muscle, of the obese niacin group compared to the obese control group indicating that PPAR $\alpha$ and/or PPAR $\delta$ was indeed activated by niacin administration. Regarding that mRNA and protein levels of OCTN2, BBD and TMABA-DH, which have been identified either as direct PPAR $\alpha$ target genes or to be regulated by PPAR $\delta[12,14-16]$, were increased in the liver and skeletal muscle of the obese niacin group compared to the obese control group suggests that activation of PPAR $\alpha$ and/or PPAR $\delta$ is responsible for this effect. Since the selected genes encoding enzymes of fatty acid $\beta$-oxidation but also other genes involved in fatty acid $\beta$-oxidation are target genes of both, PPAR $\alpha$ and PPAR $\delta$, it is not possible to differentiate whether niacin activates either PPAR $\alpha$ or PPAR $\delta$ or both of them. However, recent observations from whole-genome transcriptional profiling in PPAR $\alpha$ knockout and PPAR $\delta$ knockout mice suggested that the key regulator of fatty acid oxidation genes in the liver is PPAR $\alpha$ [35], whereas PPAR $\delta$, the predominant PPAR isoform in skeletal muscle, plays this role in skeletal muscle. It is therefore possible that the effect of niacin on OCTN2 expression in skeletal muscle is mediated by PPAR $\delta$ activation and that on OCTN2, $\mathrm{BBD}$ and TMABA-DH expression in the liver by PPAR $\alpha$ activation.

The mechanism underlying activation of PPAR $\alpha$ and/or PPAR $\delta$ by niacin remains to be resolved but it may involve an elevation of circulating levels of NEFA, which serve as PPAR ligands. Considering the well-known antilipolytic effect of niacin, an elevation of plasma NEFA levels seems paradox. However, the rapid decrease of plasma NEFA concentrations in response to acute administration of niacin is followed by a marked rebound of plasma NEFA levels to even above pre-treatment levels [36,37], which may be responsible for an increased binding to and activation of PPARs in tissues. The rebound phenomenon has been explained by the decreasing antilipolytic effect of the administrated niacin and the parallel stimulation of lipolysis by lipolytic hormones, like epinephrine and corticosterone, which are found at increased levels in plasma following niacin administration $[7,38]$. Nevertheless, based on the present data it still remains speculative if the effect of niacin on carnitine homeostasis is mediated by activation of PPARs. Definitive proof can be provided only by investigating the effect of niacin in PPAR $\alpha /$ PPAR $\delta$ doubleknockout mice in future studies.

Since there is no evidence in the literature that niacin supplementation stimulates protein catabolism in skeletal muscle, we exclude the possibility that niacin caused the improvement of carnitine status through an enhanced release of the carnitine precursor TML, which is released upon protein degradation, from skeletal muscle. In line with this assumption, we found no difference in the TML concentrations in plasma, liver and skeletal muscle, the main source of TML, between the obese control and the obese niacin group.

\section{Conclusion}

Our study shows for the first time that niacin administration is able to improve the diminished carnitine status of obese Zucker rats, an established genetic model of human obesity. The herein reported effect of niacin on the carnitine status is supposed to be beneficial in obese subjects, because it is well-known that obesity causes an impairment of carnitine status, which was evident also in the obese Zucker rats. An impaired carnitine status is generally detrimental for the metabolic situation in obese subjects, which is characterized by a chronic excess of metabolic substrates, because it contributes not only to reduced fatty acid oxidation capacity and to mitochondrial dysfunction but also to insulin resistance [20]. Thus, normalizing an impaired carnitine status is a key for 
improving the metabolic situation during obesity as evidenced from the observation that oral carnitine supplementation overcomes not only mitochondrial dysfunction but also improves glucose tolerance in different rodent models of obesity [20]. One important factor being causative for the impaired carnitine status during obesity is likely a disturbed PPAR $\alpha$ function [21] leading to a decreased capacity of the liver to synthesize and take up carnitine, because PPAR $\alpha$ is a critical transcriptional regulator of genes involved in carnitine homeostasis [12,15-18]. This is also evident from the finding that PPAR $\alpha$ knockout mice have markedly decreased levels of carnitine in tissues and plasma [39]. Thus, activation of PPAR $\alpha$ in tissues by niacin is likely responsible for the increased carnitine concentration in the liver of obese Zucker rats. In agreement with this, we have recently demonstrated that regular endurance exercise, which also causes activation of PPARs in tissues due to an elevated release of NEFA from adipose tissue, is able to restore the reduced carnitine levels in high-fat diet-induced obese mice to those levels found in non-obese sedentary mice due to activation of PPARs and PPAR co-activators in the liver and enhancing the mRNA and protein levels of genes involved in carnitine uptake and synthesis [22].

\section{Competing interests}

The authors declare that they have no competing interests.

\section{Authors' contributions}

AC carried out the molecular biological analyses, performed statistical analysis, and drafted the manuscript. RR participated in the design of the study, and helped to draft the manuscript. EM performed analysis of nicotinic acid and its metabolites. KE conceived of the study, and participated in its design and coordination and helped to draft the manuscript. All authors read and approved the final manuscript.

\section{Acknowledgements}

The authors declare that they do not have someone to acknowledge to.

Received: 25 March 2014 Accepted: 1 July 2014

Published: 9 July 2014

\section{References}

1. Gille A, Bodor ET, Ahmed K, Offermanns S: Nicotinic acid: pharmacological effects and mechanisms of action. Annu Rev Pharmacol Toxicol 2008, 48:79-106.

2. Guyton JR: Effect of niacin on atherosclerotic cardiovascular disease. Am J Cardiol 1998, 82:18U-23U. discussion 39U-41U.

3. Ganji SH, Kamanna VS, Kashyap ML: Niacin and cholesterol: role in cardiovascular disease (review). J Nutr Biochem 2003, 14:298-305.

4. Kamanna VS, Kashyap ML: Mechanism of action of niacin. Am J Cardiol 2008, 101:20B-26B.

5. Carlson LA: Nicotinic acid: the broad-spectrum lipid drug. A 50th anniversary review. J Intern Med 2005, 258:94-114.

6. Choi S, Yoon H, Oh K, Oh YT, Kim Yl, Kang I, Youn JH: Widespread effects of nicotinic acid on gene expression in insulin-sensitive tissues: implications for unwanted effects of nicotinic acid treatment. Metab Clin Exp 2011, 60:134-144.

7. Watt MJ, Southgate RJ, Holmes AG, Febbraio MA: Suppression of plasma free fatty acids upregulates peroxisome proliferator-activated receptor (PPAR) $a$ and $\delta$ and PPAR coactivator 1a in human skeletal muscle, but not lipid regulatory genes. J Mol Endocrinol 2004, 33:533-544.

8. Mandard S, Müller M, Kersten S: Peroxisome proliferator-activated receptor a target genes. Cell Mol Life Sci 2004, 61:393-416.
9. Kersten S, Seydoux J, Peters JM, Gonzalez FJ, Desvergne B, Wahli W: Peroxisome proliferator-activated receptor a mediates the adaptive response to fasting. J Clin Invest 1999, 103:1489-1498.

10. Leone TC, Weinheimer CJ, Kelly DP: A critical role for the peroxisome proliferator-activated receptor a (PPARa) in the cellular fasting response: the PPARa-null mouse as a model of fatty acid oxidation disorders. Proc Natl Acad Sci U S A 1999, 96:7473-7478.

11. Gutgesell A, Wen G, König B, Koch A, Spielmann J, Stangl Gl, Eder K, Ringseis R: Mouse carnitine-acylcarnitine translocase (CACT) is transcriptionally regulated by PPARa and PPARS in liver cells. Biochim Biophys Acta 2009, 1790:1206-1216.

12. Wen $G$, Ringseis $R$, Eder $K$ : Mouse OCTN2 is directly regulated by peroxisome proliferator-activated receptor a (PPARa) via a PPRE located in the first intron. Biochem Pharmacol 2010, 79:768-776.

13. Schoonjans K, Staels B, Auwerx J: The peroxisome proliferator activated receptors (PPARs) and their effects on lipid metabolism and adipocyte differentiation. Biochim Biophys Acta 1996, 1302:93-109.

14. Zhou X, Ringseis R, Wen G, Eder K: Carnitine transporter OCTN2 and carnitine uptake in bovine kidney cells is regulated by peroxisome proliferator-activated receptor $\beta / \delta$. Acta Vet Scand 2014, 56:21.

15. Wen $G$, Kühne $H$, Rauer $C$, Ringseis $R$, Eder K: Mouse $\gamma$-butyrobetaine dioxygenase is regulated by peroxisome proliferator-activated receptor a through a PPRE located in the proximal promoter. Biochem Pharmacol 2011, 82:175-183.

16. Wen G, Ringseis R, Rauer C, Eder K: The mouse gene encoding the carnitine biosynthetic enzyme 4-N-trimethylaminobutyraldehyde dehydrogenase is regulated by peroxisome proliferator-activated receptor a. Biochim Biophys Acta 1819, 2012:357-365.

17. Ringseis $R$, Pösel $S$, Hirche F, Eder K: Treatment with pharmacological peroxisome proliferator-activated receptor a agonist clofibrate causes upregulation of organic cation transporter 2 in liver and small intestine of rats. Pharmacol Res 2007, 56:175-183.

18. Ringseis R, Lüdi S, Hirche F, Eder K: Treatment with pharmacological peroxisome proliferator-activated receptor a agonist clofibrate increases intestinal carnitine absorption in rats. Pharmacol Res 2008, 58:58-64.

19. Ringseis R, Rosenbaum S, Gessner DK, Herges L, Kubens JF, Mooren F, Krüger K, Eder K: Supplementing obese Zucker rats with niacin induces the transition of glycolytic to oxidative skeletal muscle fibers. J Nutr 2013, 143:125-131.

20. Noland RC, Koves TR, Seiler SE, Lum H, Lust RM, Ilkayeva O, Stevens RD, Hegardt FG, Muoio DM: Carnitine insufficiency caused by aging and overnutrition compromises mitochondrial performance and metabolic control. J Biol Chem 2009, 284:22840-22852.

21. Koves TR, Ussher JR, Noland RC, Slentz D, Mosedale M, Ilkayeva O, Bain J, Stevens R, Dyck JRB, Newgard CB, Lopaschuk GD, Muoio DM: Mitochondrial overload and incomplete fatty acid oxidation contribute to skeletal muscle insulin resistance. Cell Metab 2008, 7:45-56.

22. Ringseis R, Mooren F, Keller J, Couturier A, Wen G, Hirche F, Stangl Gl, Eder K, Krüger K: Regular endurance exercise improves the diminished hepatic carnitine status in mice fed a high-fat diet. Mol Nutr Food Res 2011, 55(Suppl 2):S193-S202.

23. Reeves PG, Nielsen FH, Fahey GC: AIN-93 purified diets for laboratory rodents: final report of the American Institute of Nutrition ad hoc writing committee on the reformulation of the AIN-76A rodent diet. J Nutr 1993, 123:1939-1951.

24. Liu M, Zhang D, Wang X, Zhang L, Han J, Yang M, Xiao X, Zhang Y, Liu H: Simultaneous quantification of niacin and its three main metabolites in human plasma by LC-MS/MS. J Chromatogr B Analyt Technol Biomed Life Sci 2012, 904:107-114.

25. Scholz K, Kynast AM, Couturier A, Mooren F, Krüger K, Most E, Eder K, Ringseis $R$ : Supplementing healthy rats with a high-niacin dose has no effect on muscle fiber distribution and muscle metabolic phenotype. Eur J Nutr. Epub ahead of print.

26. Hirche F, Fischer M, Keller J, Eder K: Determination of carnitine, its short chain acyl esters and metabolic precursors trimethyllysine and gamma-butyrobetaine by quasi-solid phase extraction and MS/MS detection. J Chromatogr B Analyt Technol Biomed Life Sci 2009, 877:2158-2162.

27. Keller J, Ringseis R, Priebe S, Guthke R, Kluge H, Eder K: Dietary L-carnitine alters gene expression in skeletal muscle of piglets. Mol Nutr Food Res 2011, 55:419-429. 
28. Li D, Tian Y, Guo J, Sun W, Lun Y, Guo M, Luo N, Cao Y, Cao J, Gong X, Zhou S: Nicotinamide supplementation induces detrimental metabolic and epigenetic changes in developing rats. Br J Nutr 2013, 110:2156-2164.

29. Kirkland JB: Niacin status, NAD distribution and ADP-ribose metabolism. Curr Pharm Des 2009, 15:3-11.

30. Mullangi R, Srinivas NR: Niacin and its metabolites: role of LC-MS/MS bioanalytical methods and update on clinical pharmacology. An overview. Biomed Chromatogr 2011, 25:218-237.

31. Rebouche CJ, Bosch EP, Chenard CA, Schabold KJ, Nelson SE: Utilization of dietary precursors for carnitine synthesis in human adults. J Nutr 1989, 119:1907-1913.

32. Tamai I, Ohashi R, Nezu J, Yabuuchi H, Oku A, Shimane M, Sai Y, Tsuji A: Molecular and functional identification of sodium ion-dependent, high affinity human carnitine transporter OCTN2. J Biol Chem 1998, 273:20378-20382.

33. Tamai I, Ohashi R, Nezu Jl, Sai Y, Kobayashi D, Oku A, Shimane M, Tsuji A: Molecular and functional characterization of organic cation/carnitine transporter family in mice. J Biol Chem 2000, 275:40064-40072.

34. Vaz FM, Wanders RJA: Carnitine biosynthesis in mammals. Biochem J 2002, 361:417-429.

35. Sanderson LM, Boekschoten MV, Desvergne B, Müller M, Kersten S: Transcriptional profiling reveals divergent roles of PPARa and PPAR $\beta / \delta$ in regulation of gene expression in mouse liver. Physiol Genomics 2010, 41:42-52.

36. Oh YT, Oh K, Choi YM, Jokiaho A, Donovan C, Choi S, Kang I, Youn JH: Continuous 24-h nicotinic acid infusion in rats causes FFA rebound and insulin resistance by altering gene expression and basal lipolysis in adipose tissue. Am J Physiol Endocrinol Metab 2011, 300:E1012-E1021.

37. Poynten AM, Gan SK, Kriketos AD, O'Sullivan A, Kelly JJ, Ellis BA, Chisholm $D J$, Campbell LV: Nicotinic acid-induced insulin resistance is related to increased circulating fatty acids and fat oxidation but not muscle lipid content. Metab Clin Exp 2003, 52:699-704.

38. Quabbe HJ, Luyckx AS, L'age M, Schwarz C: Growth hormone, cortisol, and glucagon concentrations during plasma free fatty acid depression: different effects of nicotinic acid and an adenosine derivative (BM 11.189). J Clin Endocrinol Metab 1983, 57:410-414.

39. Koch A, König B, Stangl Gl, Eder K: PPARa mediates transcriptional upregulation of novel organic cation transporters-2 and -3 and enzymes involved in hepatic carnitine synthesis. Exp Biol Med (Maywood) 2008, 233:356-365.

doi:10.1186/2050-6511-15-37

Cite this article as: Couturier et al:: Pharmacological doses of niacin stimulate the expression of genes involved in carnitine uptake and biosynthesis and improve the carnitine status of obese Zucker rats. BMC Pharmacology and Toxicology 2014 15:37.

\section{Submit your next manuscript to BioMed Central and take full advantage of:}

- Convenient online submission

- Thorough peer review

- No space constraints or color figure charges

- Immediate publication on acceptance

- Inclusion in PubMed, CAS, Scopus and Google Scholar

- Research which is freely available for redistribution 